\title{
ИСПОЛЬЗОВАНИЕ ЭЛЕКТРОННЫХ УСТРОЙСТВ УЧАСТНИКАМИ ОБРАЗОВАТЕЛЬНОГО ПРОЦЕССА ПРИ ТРАДИЦИОННОЙ И ДИСТАНЦИОННОЙ ФОРМАХ ОБУЧЕНИЯ
}

О. Ю. Милушкина', В. И. Попов², Н. А. Скоблина', С. В. Маркелова ${ }^{1}$, Н. В. Соколова ${ }^{3}$

1 Российский национальный исследовательский медицинский университет имени Н. И. Пирогова, Москва, Россия

2 Воронежский государственный медицинский университет имени Н. Н. Бурденко, Воронеж, Россия

${ }^{3}$ Воронежский государственный педагогический университет, Воронеж, Россия

Внедрение дистанционного обучения весной 2020 г. привело к увеличению интенсивности использования информационно-коммуникационных технологий участниками образовательного процесса. Цель работы - дать гигиеническую характеристику использования электронных устройств школьниками, их родителями и учителями организаций общего образования в условиях различных режимов обучения (традиционного и дистанционного). В исследовании посредством онлайн-опроса приняли участие 200 школьников, 389 учителей и 251 родитель в период традиционного обучения, 658 учителей и 500 родителей - в период дистанционного обучения. При статистической обработке результатов использовали $t$-критерий Стьюдента, критерий $\chi^{2}$, коэффициент сопряженности Пирсона, относительный риск определяли с помощью четырехпольных таблиц сопряженности, $p \leq 0,05$. В период дистанционного обучения увеличились число используемых электронных устройств у 96,6\% школьников и время работы с ними. Увеличение числа жалоб на самочувствие учащихся отметили до 80\% родителей, из них более 60\% указывали на симптомы, характерные для компьютерно-зрительного синдрома. Установлена связь между возможностью отказа от использования электронного устройства и субъективной оценкой респондентами своего зрения как «отличное» и «хорошее» (КС Пирсона 0,3; $p \leq 0,05)$. Подтвержден риск субъективной оценки зрения как «удовлетворительное» и «Плохое» при ежедневном использовании электронного устройства: для школьников - 1,13, родителей - 1,41, учителей - 1,27 (p $\leq 0,05)$. Обоснован в качестве меры профилактики нарушения зрения отказ от использования электронного устройства минимум на один день в неделю.

Ключевые слова: школьники, учителя, родители, дистанционное обучение, поведенческие риски, электронные устройства, информационнокоммуникационные технологии

Вклад авторов: О. Ю. Милушкина, В. И. Попов, Н. А. Скоблина - планирование и научное руководство, обработка материала, написание статьи; С. В. Маркелова, Н. В. Соколова - анализ литературных данных, сбор и обработка материала. Все авторы - редактирование статьи.

Соблюдение этических стандартов: исследование одобрено этическим комитетом РНИМУ имени Н. И. Пирогова (протокол № 159 от 21 ноября 2016 г.). Проведение опроса не ущемляло права человека, не подвергало опасности респондентов, соответствовало требованиям биомедицинской этики.

$\triangle$ Для корреспонденции: Светлана Валерьевна Маркелова ул. Островитянова, д. 1, г. Москва, 117997; markelova_sv@rsmu.ru

Статья получена: 14.05.2020 Статья принята к печати: 15.06.2020 Опубликована онлайн: 28.06.2020

DOI: $10.24075 /$ vrgmu.2020.037

\section{THE USE OF ELECTRONIC DEVICES BY STUDENTS, PARENTS AND TEACHERS BEFORE AND AFTER THE TRANSITION TO DISTANCE LEARNING}

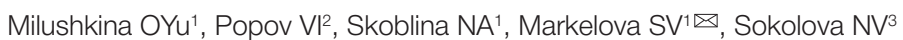

${ }_{1}^{1}$ Pirogov Russian National Research Medical University, Moscow, Russia

2 Burdenko Voronezh State Medical University, Voronezh, Russia

${ }^{3}$ Voronezh State Pedagogical University, Voronezh, Russia

Transition to distance education in spring 2020 led to the overuse of information and communication technologies by the participants of the educational process The aim of this study was to characterize the patterns of using electronic devices in high school students, their parents, and teachers in the settings of traditional brick-and-mortar education and distance learning. We created online questionnaires that were used to survey 200 high school students, 389 teachers and 251 parents before the transition to distance learning and also 658 teachers and 500 parents after the transition. Statistical analysis was conducted using Student's t test, $\chi^{2}$, and Pearson's contingency coefficient; relative risks were calculated using fourfold contingency tables. Differences were considered significant at $p \leq 0,05$. After the transition to distance learning, the number of electronic devices used by each student increased for $96.6 \%$ of the surveyed students; the average screen time also increased. About $80 \%$ of the surveyed parents reported that their children had more health complaints; of them, $60 \%$ reported symptoms typical of computer vision syndrome. We established a correlation between the readiness to cut down on screen time and the subjective assessment of vision as perfect or good by the respondents (Pearson's contingency coefficient $0.3 ; p \leq 0.05$ ). Our study confirms the relative risk for subjectively assessing one's vision as satisfactory or poor in individuals who use ED on a daily basis; the risk is 1.13 for students, 1.41 for parents, and 1.27 for teachers $(p \leq 0.05)$. The study proves that eliminating screen time from daily activities for at least one day per week is an effective measure for preventing vision disorders.

Keywords: students, teachers, parents, distance learning, health risk behavior, electronic devices, information and communication technologies

Author contribution: Milushkina OYu, Popov VI, Skoblina NA planned and supervised the study, analyzed the obtained data and wrote the manuscript; Markelova SV, Sokolova NV analyzed the literature, collected and processed the questionnaires. All authors participated in manuscript revision.

Compliance with ethical standards: the study was approved by the Ethics Committee of Pirogov Russian National Research Medical University (Protocol № 159 dated November 21, 2016). The survey did not encroach upon human rights, did not expose the respondents to any dangers and complied with the principles of biomedical ethics.

$\triangle$ Correspondence should be addressed: Svetlana V. Markelova Ostrovityanova, 1, Moscow, 117997, Russia; markelova_sv@rsmu.ru

Received: 14.05.2020 Accepted: 15.06.2020 Published online: 28.06.2020

DOI: $10.24075 /$ brsmu.2020.037 
Юридические основы реализации образовательных программ с применением электронного обучения и дистанционных образовательных технологий были впервые закреплены Федеральным законом Российской Федерации еще в 2012 г. [1]. Однако были отмечены неготовность педагогического сообщества к предложенным формам обучения и низкая гигиеническая грамотность педагогов в вопросах безопасного использования электронных устройств, профилактики их неблагоприятного воздействия на организм человека [2].

Информационно-коммуникационные технологии (ИКТ) были постепенно введены в образовательный процесс, и сегодня обучение уже нельзя представить без компьютеров и интерактивных досок, интернета, аудио- и видео ресурсов. Смартфоны, планшеты, компьютеры стали частью повседневной жизни детей, подростков и молодежи. В России около 10 млн детей в возрасте до 14 лет - активные пользователи интернета [2-6].

Многофакторность проблемы электронного обучения определяет нерешенность вопросов ее гигиенического регламентирования. Внедряемые в деятельность образовательных организаций новые формы профилактической работы не могут решить всего комплекса существующих проблем [7-11].

Эпидемиологическая ситуация, возникшая весной 2020 г., послужила основанием для спонтанного вынужденного перехода на дистанционное образование (ДО) в период самоизоляции, что повлекло за собой бесконтрольное и необоснованно широкое использование ИКТ всеми группами населения, включая учащихся. Зарубежные публикации о вынужденном переходе на ДО в основном посвящены экономическим (сокращение штата и средств), а также педагогическим аспектам (сравнение результатов итогового тестирования при традиционном обучении (ТО) и ДО), не затрагивают вопросов профилактики и увеличения жалоб на состояние здоровья обучающихся [12-13].

Массовое распространение электронных устройств (ЭУ), подкрепляемое профессиональной и социальной необходимостью, на фоне низкой грамотности населения в вопросах их безопасного использования служит предпосылкой к увеличению числа заболеваний по целому ряду нозологий. В литературных данных представлены сведения об ухудшении психофизиологического состояния молодежи: повышении среди пользователей ЭУ нервноэмоционального напряжения, раздражительности, нарушениях сна, появлении зависимости [14-19]. Ограничение двигательной активности, неудобная статическая поза негативно сказываются на состоянии опорно-двигательной, дыхательной и сердечно-сосудистой систем, снижается внимание, ослабляется память [20-23]. Качество изображения на экране монитора, удаленность экрана от глаз, уровень освещенности рабочей поверхности, время непрерывной работы с ЭУ являются факторами риска развития заболеваний органов зрения [24-27].

Высокие уровни заболеваний органов зрения, отмечаемые на протяжении последних 15 лет среди детей и подростков, тоже совпали с массовым распространением ЭУ [28-29]

Возросли объемы информационных нагрузок на обучающихся, связанные с увеличением частоть использования ИКТ посредством применения стационарных и мобильных ЭУ. При этом существующие на сегодняшний день гигиенические требования по регламентации продолжительности применения ЭУ в образовательном процессе не выполняются [28].

Использование ЭУ любой категорией населения, особенно детьми, должно предусматривать информированность о возможном негативном влиянии ЭУ на здоровье и ссормированность навыков их безопасного использования, особенно при дистанционном обучении, когда отсутствует контроль со стороны учителя за соблюдением гигиенических требований. Данная ситуация накладывает большую ответственность на родителей, которые должны обладать знаниями в вопросах здоровьесбережения и создать ребенку дома максимально комфортные условия для обучения с точки зрения сохранения его здоровья.

В настоящее время в России исследование гигиенических аспектов массового перехода в 2020 г. на ДО не проводили.

Целью исследования было дать гигиеническую характеристику использования ЭУ школьниками, их родителями и учителями организаций общего образования в условиях различных режимов обучения (традиционного и дистанционного).

\section{МАТЕРИАЛЫ И МЕТОДЫ}

На кафедре гигиены педиатрического факультета РНИМУ им. Н. И. Пирогова преподавателями, имеющими сертисикат специалиста «Гигиеническое воспитание», «Гигиена детей и подростков», «Общая гигиена», было разработано пять вариантов опросников, размещенных на онлайн-сервисе Google Forms. Чувствительность онлайн-анкет по отношению к бланковому опросу составила не менее 82\% (DI: 80,5-83,5), специфичность не менее 90\% (DI: 88,1-92,2). Анкеты имели четкую адресованность в период ТО (для школьников, родителей и учителей, Приложение 1) и в период ДО (для родителей и учителей, Приложение 2). Критерии включения в исследование: принадлежность респондента к школьникам, родителям школьника, учителям организации общего образования; корректность заполнения формы. Критерии исключения: отсутствие принадлежности к опрашиваемой категории респондентов; некорректное заполнение опросника. Опросники включали блоки: «паспортная часть»; «здоровье»; вопросы, характеризующие особенности использования ИКТ с применением стационарных и мобильных ЭУ; сформированность практических навыков безопасного использования ЭУ.

\section{Проведение традиционного обучения в 2019 г.}

В период ТО опросили 200 школьников 9-11 классов из восьми субъектов РФ, включая города-миллионники; 43\% проходили обучение в организациях общего образования, остальные - в гимназиях, лицеях, школах с углубленным изучением предметов и пр.

Среди 251 родителя, проживающего в 15 субъектах РФ, включая города-миллионники, основная доля (86\%) относилась к возрастной группе 30-49 лет. Более 85\% из них - женщины.

Среди 389 учителей, проживающих в 25 субъектах РФ, включая города-миллионники, наибольшая доля относилась к возрастной группе 40-49 лет (31\%). Более 90\% из них — женщины. 


\section{Проведение дистанционного обучения в 2020 г.}

В этот период опросили 500 родителей более чем из 15 регионов РФ, включая города-миллионники. Основную долю составляли женщины (более 90\%). Доля опрошенных, относящихся к возрастной группе 30-49 лет, - 89\%.

Проводили опрос 658 учителей более чем из 30 регионов РФ, включая города-миллионники. Основную долю среди них составили женщины (более 85\%). Наибольшая часть опрошенных относилась к возрастной группе 40-49 лет (32\%).

Статистическую обработку данных проводили с использованием пакета прикладных программ Statistica 13.0. (StatSoft Inc.; СШA). Использовали $t$-критерий Стьюдента, критерий $\chi^{2}$, коэффициент сопряженности Пирсона. Относительный риск (RR-вероятность появления определенного исхода в зависимости от фрактора среды) определяли с использованием четырехпольных таблиц сопряженности. Критический уровень значимости принимался равным 0,05.

\section{РЕЗУЛЬТАТЫ ИССЛЕДОВАНИЯ}

В период ТО респондентам были предложены вопросы, касающиеся наличия практических навыков безопасного применения ЭУ и профилактики нарушения здоровья, обусловленного работой с ними.

Установлено, что при использовании ЭУ большинство школьников и родителей (64,5 и 63,0\% соответственно) не делают рекомендуемый перерыв в работе каждый час, а каждый шестой школьник $(17,0 \%)$ и родитель $(17,5 \%)$ работают с ЭУ вообще без перерыва (табл. 1).

Среди учителей не прерывают работу с ЭУ каждый час более половины $(53,1 \%)$ и каждый седьмой $(15,2 \%)$ работает без перерыва вообще (см. табл. 1).

Выявлено, что только каждый восьмой школьник (13\%) и родитель $(12,7 \%)$ предпочтут воздержаться от работы с ЭУ в условиях недостаточной освещенности, что соответствует гигиеническим рекомендациям, в то время как каждый третий школьник (37\%) и каждый пятый родитель (20,7\%) продолжат работать при любых условиях (см. табл. 1).

Каждый пятый учитель (18,8\%) отметил, что прекратит работу с ЭУ в условиях недостаточной освещенности, а каждый восьмой (12,9\%) продолжит ее при любых условиях (см. табл. 1).

Большинство педагогов (86,6\%) считают необходимым проведение среди подрастающего поколения работы по формированию здорового образа жизни начиная с раннего детского возраста. В то же время почти треть учителей (26,5\%) во время уроков не проводят динамических пауз, а около половины $(44,4 \%)$ — гимнастику для глаз, т. е. не предпринимают действий, направленных на охрану зрения школьников в рамках имеющихся должностных обязанностей. При этом большинство опрошенных учителей $(67,5 \%)$ отмечают у современных школьников наличие проблем со здоровьем.

Субъективная оценка качества своего зрения, проведенная в период ТО, показала, что около половины школьников $(51 \%)$ и родителей $(48,6 \%)$ оценивают свое зрение как "Отличное» (24,5 и 19,5\% соответственно) и «хорошее» (26,5 и 29,1\% соответственно). Каждый шестой школьник (18,0\%) и каждый третий родитель $(31,5 \%)$ оценили его на «удовлетворительно»; указали, что зрение у них «плохое», каждый третий школьник $(31,0 \%)$ и каждый пятый родитель (19,9\%). Опрос, проведенный среди учителей, показал, что из них оценивают свое зрение как «отличное» 10,7\%, «хорошее» - 29,9\%, «удовлетворительное» - 46,0\%, «плохое» - 13,4\% (см. табл. 1).

Указали, что не нуждаются в коррекции зрения только половина школьников (49,0\%), доля которых соотносится с количеством учащихся, оценивших свое зрение как "отличное» и «хорошее». При работе с ЭУ только 5,5\% школьников отметили, что пользуются специально подобранными очками, в то время как остальные либо отрицали использование специально подобранных очков, либо отмечали, что никогда очками не пользовались (см. табл. 1).

Аналогичный опрос родителей и учителей показал, что 47,4 и 40,6\% из них соответственно не нуждаются в коррекции зрения, что сопоставимо с долей респондентов, оценивших свое зрение как “отличное» и "хорошее». При работе с ЭУ только 7,5\% родителей и 11,0\% учителей пользуются специально подобранными очками, остальные ими не пользуются, хотя этого и требует острота их зрения, или пользуются очками, не предназначенными для работы с ЭУ, например, подобранными «для взора вдаль» (см. табл. 1).

Путем построения таблиц сопряженности установлено, что около 50\% школьников, родителей и учителей не уделяют должного внимания проблеме снижения у них остроты зрения, используют неэффективные средства коррекции зрения при работе с ЭУ ( $p \leq 0,05)$.

Проведенный опрос позволил распределить респондентов на группы в зависимости от возможности отказа от использования ЭУ (табл. 2).

Сравнительная оценка результатов опроса родителей и учителей выявила достоверные различия в субъективной оценке респондентами качества своего зрения, а также в возможности отказаться от использования ЭУ на день в неделю и более ( $p \leq 0,05)$ (см. табл. 2).

Среди школьников, родителей и учителей, указавших, что не могли бы обойтись без ЭУ ни одного дня, треть $(37,5$, 38,1 и 36,0\% соответственно) субъективно оценивали свое зрение как "отличное» и "хорошее», а среди тех, кто мог бы обойтись без ЭУ больше трех дней, таких ответов было достоверно больше $(64,0,58,75$ и 48,0\% соответственно) $(p \leq 0,05)$.

Таблица 1. Субъективная оценка своего зрения и распространенность поведенческих факторов риска бесконтрольного использования ЭУ школьниками, родителями и учителями в период традиционного обучения, \%

\begin{tabular}{|l|c|c|}
\hline \multicolumn{1}{|c|}{ Фактор риска } & Школьники & Родители \\
\hline Отсутствие рекомендованных перерывов в работе & $64,5 \pm 3,4$ & $63,0 \pm 3,1$ \\
\hline Работа с ЭУ в условиях недостаточного освещения & $87,0 \pm 2,4$ & $87,3 \pm 2,1$ \\
\hline Использование очков, специально подобранных для работы с ЭУ & $81,2 \pm 2,0^{*}$ \\
\hline Субъективная оценка своего зрения как «удовлетворительное» и «плохое» & $49,5 \pm 1,6$ & $7,5 \pm 1,7$ \\
\hline
\end{tabular}

Примечание: * - различия достоверны, $p \leq 0,05$. 
Таблица 2. Субъективная оценка респондентами своего зрения и доля школьников, родителей и учителей, допускающих отказ от использования ЭУ, \%

\begin{tabular}{|l|c|c|c|}
\hline \multicolumn{1}{|c|}{ Отказ от использования Эу } & Школьники & Родители & Учителя \\
\hline - не допускают & $24,0 \pm 3,0$ & $41,8 \pm 3,1$ & $38,4 \pm 2,5$ \\
\hline - допускают на 1-3 дня & $38,5 \pm 3,4$ & $33,1 \pm 3,0$ & $47,8 \pm 2,5^{\star}$ \\
\hline - допускают на 3 дня и больше & $37,5 \pm 3,4$ & $25,1 \pm 2,7$ & $33,5 \pm 2,4^{*}$ \\
\hline Субъективная оценка своего зрения как «хорошее» и «отличное» & $51,0 \pm 3,5$ & $48,6 \pm 3,2$ & $40,6 \pm 2,5^{\star}$ \\
\hline
\end{tabular}

Примечание: * - различия достоверны, $p \leq 0,05$.

Установлена связь между возможностью отказа от использования ЭУ и субъективной оценкой респондентами своего зрения как “Отлично" и “хорошо» (коэффициент сопряженности Пирсона 0,3; $p \leq 0,05)$.

В период ДО отмечено достоверное увеличение числа ЭУ, используемых школьниками для целей обучения (табл. 3).

В период ДО время работы школьников с ЭУ тоже увеличилось. По мнению родителей, оно возросло на 2 ч у $15,0 \%$ школьников, на 3 ч у 20,8\%, на 4 ч у 18,6\%, на 5 ч у $10,0 \%$, на 6 ч и более часов у 25,0\% учащихся.

При этом у учителей среднее время использования мобильных ЭУ, согласно приложению «Экранное время», в период ТО составило 5,0 \pm 0,3 ч, а в период проведения ДО - 8,0 $\pm 0,3$ ч $(p \leq 0,01)$.

По субъективной оценке подавляющего большинства родителей (80\%), в период ДО увеличилось число жалоб школьников на самочувствие. По характеру проявлений жалобы можно разделить на группы, характерные для компьютерно-зрительного синдрома (усталость глаз $60,6 \%$, боли в области глаз - 27,0\%, расплывчатость изображения - 19,4\%, ощущение мелькания перед глазами - 11,4\%, ощущение песка в глазах - 16,2\%), нарушений опорно-двигательного аппарата (боль в спине - 37,6\%, боль в шее - 31,8\%), поражений нервнопсихической сферы (головные боли - 40,2\%, тяжесть в голове - 21,0\%, заложенность и шум в ушах - 7,8\%, быстро развивающееся утомление - 58,0\%, нервнопсихическое напряжение - 49,8\%, нарушения режима сна и трудности засыпания - 30,4\%). Только 17,2\% школьников жалоб не имели.

В ходе оценки риска здоровью использования ИКТ установлены статистически значимые величины относительного риска для субъективной оценки зрения как «удовлетворительное» и «Плохое» от различной частоты использования ЭУ (ежедневно или при наличии перерывов в 1-3 дня и более). Величина относительного риска для субъективной оценки зрения «удовлетворительное» и «Плохое» при ежедневном использовании ЭУ у школьников составила 1,13 (DI: 1,07-1,47); у родителей - 1,41 (DI: 1,11-1,79); для учителей - 1,27 (DI: 1,07-1,52).

\section{ОБСУЖДЕНИЕ РЕЗУЛЬТАТОВ}

Активно развивающиеся на протяжении последних 20 лет ИКТ на базе различных ЭУ получили широкое распространение в повседневной жизни и образовательном процессе. Эпидемиологическая ситуация, возникшая весной 2020 г., способствовала введению ДО в работу организаций общего образования.

Ранее, в период ТО, было показано, что только 0,5\% учащихся не имеют доступа к ЭУ, остальные применяют от одного до нескольких ЭУ ежедневно. Продолжительность использования ЭУ школьниками сопоставима с использованием ЭУ взрослыми пользователями и составляет 7-10 ч в день в зависимости от возраста, пола, учебного или каникулярного периода [19, 25]. Увеличивается продолжительность использования ЭУ [30].

В период ДО практически у всех учащихся (96,6\%) увеличилось число используемых ЭУ от одного до трех и более ( $0 \leq 0,05)$ (см. табл. 3), возросло время работы с ними от 2 ч (15,0\% школьников) до 6 ч и более (у 25,0\%). В результате большинство родителей (80\%) отметило увеличение числа жалоб на плохое самочувствие школьников. Наибольшее число жалоб (60\%) вписывалось в клиническую картину компьютерно-зрительного синдрома, поражения опорно-двигательного аппарата и нервнопсихических нарушений.

Согласно мобильному приложению «Экранное время», продолжительность работы с ЭУ учителей увеличилась на З ч в день $(p \leq 0,01)$.

Подобная ситуация является следствием бесконтрольного использования ЭУ, возникшего в том числе в результате введения режима "самоизоляции" и вынужденного перехода на ДО, использования неадаптированных для ДО образовательных технологий и программ по причине их отсутствия. Также необходимо отметить отсутствие четких критериев регламентирования времени работы с ЭУ в зависимости от возраста, периода обучения (учебный или каникулярный), требований безопасности к качеству изображения на экране, недостаточность критериев оценки технических характеристик ЭУ, а также низкую информированность населения и отсутствие сформированности у него навыков безопасного использования ЭУ.

«В ходе исследования среди всех групп респондентов отмечена высокая потребность в использовании ЭУ. Каждый четвертый школьник (24,0\%), каждый второй родитель $(41,8 \%)$ и каждый третий учитель $(38,4)$ не готовы отказаться от ежедневного использования ЭУ (см. табл. 2).

Опрос учителей, школьников и их родителей, проведенный в периоды ТО и ДО, выявил наличие поведенческих факторов риска для здоровья от

Таблица 3. Доля школьников, использующих различное число ЭУ при традиционной и дистанционной формах обучения, по данным опроса родителей, \%

\begin{tabular}{|l|c|c|}
\hline \multicolumn{1}{|c|}{ Число используемых при обучении Эу } & Традиционное обучение & Дистанционное обучение \\
\hline Не используют ЭУ & 36 & $3,4^{*}$ \\
\hline Используют одно ЭУ & 47,4 & $29,8^{\star}$ \\
\hline Используют два ЭУ & 11,4 & $51,8^{\star}$ \\
\hline Используют три и более ЭУ & 5,2 & $15,0^{\star}$ \\
\hline
\end{tabular}

Примечание: * - различия достоверны, $p \leq 0,05$. 
бесконтрольного использования ИКТ посредством применения различных видов ЭУ.

Установлено несоблюдение правил безопасного использования ЭУ большинством респондентов: отсутствие перерыва после каждого часа работы с ЭУ (64,5\% школьников, 63,0\% родителей, 53,1\% учителей); работа в условиях недостаточной освещенности $(87,0$, 87,3 и 81,2\% соответственно); отсутствие необходимых средств коррекции зрения или использование очков, не предназначенных для работы с ЭУ (45,5\%, 44,8\% и 48,4\% соответственно).

Доказано более широкое распространение поведенческих факторов риска бесконтрольного использования ЭУ среди родителей школьников в сравнении с учителями ( $p \leq 0,05)$, а также более частая субъективная оценка ими своего зрения как «удовлетворительное» и «плохое» $(p \leq 0,05)$ (см. табл. 1).

Роль семьи, образовательной организации, личный пример родителей и учителей в формировании основ безопасного использования ЭУ очевидны. Установлена низкая настороженность респондентов $\mathrm{K}$ этой проблеме, что требует повышения эфффективности мер просветительного характера среди учителей, родителей и учащихся. Особую актуальность приобретает повышение информированности родителей об основах безопасного использования ЭУ в связи с распространением электронного обучения, снижением контролирующей функции учителя, увеличением доли ИКТ в досуговом времени детей.

Большинство учителей указывают на наличие у детей нарушений в состоянии здоровья $(67,5 \%)$, осознают потребность в формировании у них основ здорового образа жизни, к которым относится и безопасность работы с ЭУ (86,6\%). В то же время, вопреки имеющимся профессиональным обязанностям, треть педагогов (26,5\%) не проводит с детьми во время уроков динамические паузы, а каждый второй учитель $(44,4 \%)$ - гимнастику для глаз. Вероятно, подобная ситуация стала возможной вследствие низкой заинтересованности учителей в соблюдении гигиенических требований, высокой интенсивности образовательного процесса.

Следствием недостаточной информированности населения является и отмеченная среди $50 \%$ респондентов низкая настороженность в вопросах профилактики уже имеющихся нарушений зрения, обусловленных в том числе использованием неэффективных средств коррекции зрения при работе с ЭУ ( $p \leq 0,05)$.

Ранее было доказано наличие риска возникновения миопии средней и высокой степеней $(R R$ - 6,62) в зависимости от частоты использования ноутбука и компьютера $(p \leq 0,05)$ [25].

Изучение зависимости между возможностью отказа респондента от использования ЭУ и субъективной оценкой качества своего зрения на “хорошо» и “Отлично» позволяет говорить о наличии действенного механизма профилактики нарушения зрения у пользователей ЭУ путем регламентирования времени работы с ним. Так, среди респондентов, допускающих отказ от использования ЭУ в течение одного дня в неделю и более, доля субъективных оценок качества зрения на «хорошо» и «отлично» оказалась достоверно больше $(p \leq 0,05)$.
Установлено наличие статистически значимых величин относительного риска (RR) возникновения состояния, субъективно характеризующегося как «удовлетворительное» и «плохое» зрение, от ежедневного использования ЭУ: для школьников - 1,13, для родителей $-1,41$, для учителей $1,27(p \leq 0,05)$.

Таким образом, можно констатировать выявление управляемого с точки зрения гигиенических принципов поведенческого фрактора риска - ежедневное использование ЭУ.

Полученные данные позволяют рекомендовать как в период проведения ТО, так и в период ДО в качестве мероприятия по профилактике неблагоприятного влияния факторов риска использования ИКТ с применением различных ЭУ введение регуляторного механизма, направленного на сокращение времени использования ЭУ, вплоть до отказа от их применения минимум на один день в неделю. Данное мероприятие позволит не только сократить время контакта с неблагоприятными факторами, но и выделить в режиме дня время для занятий физической активностью и спортом, что, безусловно, повысит эффективность мер профилактики путем улучшения образа жизни, а значит окажет благоприятное воздействие на здоровье населения.

Повысив информированность населения в вопросах безопасного использования ЭУ, предложив эффективные меры учета и контроля времени работы с ЭУ, возможно ожидать увеличения числа респондентов с сформированными навыками безопасного использования ЭУ.

\section{ВЫВОДЫ}

1. Выявлены поведенческие факторы риска бесконтрольного использования ИКТ всеми участниками образовательного процесса, особенно в период вынужденного перехода на ДО: отсутствие перерывов в работе с ЭУ, работа в условиях недостаточной освещенности, отсутствие специально подобранных средств коррекции зрения для работы с ЭУ, ежедневное использование ЭУ, длительность непрерывной работы с ЭУ, количество используемых ЭУ. 2. В период ДО по сравнению с ТО у школьников увеличились количество используемых ЭУ и длительность их применения, возросло число жалоб на самочувствие. Увеличилось время использования ЭУ учителями. 3. Показана достоверно более низкая сформированность навыков безопасного использования ЭУ у родителей, что не позволяет им быть примером для подражания, а также контролировать безопасность использования ЭУ детьми дома. 4. Доказана эффективность отказа от использования ЭУ на один день в неделю и более с целью профилактики нарушения зрения. 5. Обоснована необходимость расширения спектра учебных дисциплин, направленных на формирование у обучающихся компетенций здоровьесбережения и гигиенического способа мышления в вопросах цифровой безопасности, а также обучения по данной теме педагогов, формирования культуры и навыков использования ЭУ родителями. 
1. Федеральный закон «Об образовании в Российской Федерации» № 273 ФЗ от 29.12.2012. Доступно по ссылке: http://www.consultant.ru/document/cons_doc_LAW_140174/.

2. Кучма В. Р. Декларация о гигиенической безопасности для детей и подростков цифровой среды. Вопросы школьной и университетской медицины. 2014; 3: 62-63.

3. Кучма В. Р., Сухарева Л. М., Храмцов П. И. Гигиеническая безопасность жизнедеятельности детей в цифровой среде. Здоровье населения и среда обитания. 2016; 8 (281): 4-7.

4. Бухтияров И. В., Денисов Э. И., Еремин А. Л. Основы информационной гигиены: концепции и проблемы инноваций. Гигиена и санитария. 2014; 93 (4): 5-9.

5. Большаков А. М., Крутько В. Н., Кутепов Е. Н., Мамиконова О. А., Потемкина Н. С., Розенблит С. И. и др. Информационные нагрузки как новый актуальный раздел гигиены детей и подростков. Гигиена и санитария. 2016; 2: 172-7.

6. Саньков С. В. Гигиеническая безопасность электронной информационно-образовательной среды в современной школе (научный обзор). Вопросы школьной и университетской медицины и здоровья. 2018; 2: 13-20.

7. Концепция информационной безопасности детей. Распоряжение правительства РФ № 2471-р (02 декабря 2015). Доступно по ссылке: http://static.government.ru/media/ files/mPbAMyJ29uSPhL3p20168GA6hv3CtBxD.pdf.

8. Янушанец О. И., Петрова Н. А., Беззубенкова Е. Ф., Нелюбова Е. А., Широкова А. Ю. Гигиеническая оценка технического оснащения реализации информационных технологий, используемых в обучении школьников. В сборнике: Профилактическая медицина-2019: сборник научных трудов Всероссийской научно-практической конференции с международным участием. 14-15 ноября 2019 года. СПб.: Изд-во СЗГМУ им. И. И. Мечнико-ва, 2019: 244-50.

9. Кучма В. Р., Сухарева Л. М., Храмцов П. И. Современные подходы к обеспечению гигиенической безопасности жизнедеятельности детей в гиперинформационном обществе. Вопросы школьной и университетской медицины и здоровья. 2015; 3: 22-27.

10. Кучма В. Р., Текшева Л. М., Курганский А. М., Петренко А. О. Гигиеническая оценка использования ридеров в начальной школе. Гигиена и санитария. 2014; 93 (3): 57-60.

11. Кучма В. Р., Рапопорт И. К., Соколова С. Б., Александрова И. Э., Макарова А. Ю., Мустафаева К.Ш. и др. Распространенность и оценка использования электронных устройств в учебной и досуговой деятельности школьников 7-8 классов. Сеченовский вестник. 2015; 3 (21): 43-50.

12. Laks M, Guerra CM, Miraglia JL, Medeiros EA. Distance Learning in Antimicrobial Stewardship: Innovation in Medical Education. PMID: 31174524; PMCID: PMC6555969; DOI: 10.1186/s12909019-1623-x.

13. Maria B, Oleksandr K, Valentina E, Olena Y. Distance-pedagogical technologies in olympic education for schoolchildren Journal of Physical Education and Sport. Journal of Physical Education and Sport. 2019; 378 (4): 2497-503. Ukraine.

14. Дружилов С. А. Гигиенические аспекты информационнотехнологической зависимости человека в новой реальности. Гигиена и санитария. 2019; 98 (7): 748-53.

15. Смирнова А. А., Синогина Е. С. Влияние компьютера и сети интернет на физическое и психическое здоровье школьников. Народное образование. 2017; 1 (2): 199-204.

\section{References}

1. Federal'nyj zakon «Ob obrazovanii v Rossijskoj Federacii» \# 273 FZ ot 29.12.2012. Avialable from: http://www.consultant.ru/ document/cons_doc_LAW_140174/. Russian.

2. Kuchma VR. Deklaracija o gigienicheskoj bezopasnosti dlja detej i podrostkov cifrovoj sredy. Voprosy shkol'noj i universitetskoj mediciny. 2014; 3: 62-63. Russian.
16. Кучма В. Р., Ткачук Е. А., Тармаева И. Ю. Психосиизиологическое состояние детей в условиях информатизации их жизнедеятельности и интенсификации образования. Гигиена и санитария. 2016; 12: 1183-8.

17. Lemola S, Perkinson-Gloor N, Brand S, Dewald-Kaufmann JF, Grob A. Adolescents' electronic media use at night, sleep disturbance, and depressive symptoms in the smartphone age. $J$ Youth Adolesc. 2015; 44 (2): 405-18.

18. Шутова Н. В., Баранова Ю. М. Оценка риска интернетзависимости для психического здоровья подростков. Гигиена и санитария. 2017; 96 (6): 568-72.

19. Кучма В. Р., Степанова М. И., Сазанюк З. И., Поленова М. А., Александрова И. Э., Березина Н. О. и др. Гигиеническая оценка влияния учебных изданий с использованием электронных планшетов на функциональное состояние учащихся. Сеченовский вестник. 2015; 3 (21): 35-42.

20. Rideout VJ, Foehr UG, Roberts DF. Generation M2: Media in the Lives of 8- to 18-Year-Old. Henry J. Kaiser Family Foundation, Menlo Park, California. 2010. Available from: http://www.kff.org/ entmedia/upload/8010.pdf.

21. Pope-Ford R. Back flexion and extension: The effects of static posture on children using mobile devices. In: Advances in Intelligent Systems and Computing. AHFE International Conference on Safety Management and Human Factors, 2018; Orlando; United States; 21-25 July 2018. 2019; 791: 342-51.

22. Бутуханов В. Д. К вопросу валеологических проблем двигательной активности и здоровья школьников. Бюллетень Восточно-Сибирского научного центра Сибирского отделения Российской академии наук. 2009; 2: 227-8.

23. Милушкина О. Ю., Скоблина Н. А., Маркелова С. В., Татаринчик А. А., Бокарева Н. А., Федотов Д. М. Оценка рисков здоровью школьников и студентов при воздействии обучающих и досуговых информационно-коммуникационных технологий. Анализ риска здоровью. 2019; 3: 135-43.

24. Wimalasundera S. Computer vision syndrome. Galle Medical. 2006; 11 (1): 201-4.

25. Скоблина Н. А., Милушкина О. Ю., Татаринчик А. А., Федотов Д. М., Цамерян А. П., Добрук И. В. и др. Гигиенические проблемы охраны зрения школьников и студентов в условиях гиперинформационного общества. Российская детская офртальмология. 2017; 4: 5-9.

26. Текшева Л. М., Элькснина Е. В., Перминов М. А. Гигиенические аспекты использования компьютерных средств обучения в системе общего образования. Гигиена и санитария. 2007; 4: 65-69.

27. Маркелова С. В. Роль печатных и электронных изданий в формировании функциональных нарушений и хронических заболеваний органа зрения обучающихся. Фундаментальная и клиническая медицина. 2019; 4 (4): 97-104.

28. Кучма В. Р., Сухарева Л. М., Рапопорт И. К., Шубочкина Е. И., Скоблина Н. А., Милушкина О. Ю. Популяционное здоровье детского населения, риски здоровью и санитарноэпидемиологическое благополучие обучающихся: проблемы, пути решения, технологии деятельности. Гигиена и санитария. 2017; 96 (10): 990-5.

29. Здравоохранение в России 2017: статистический сборник. Росстат. М., 2017. Доступно по ссылке: https://www.gks.ru/ storage/mediabank/zdrav17.pdf.

30. Лукьянец Г. Н., Макарова Л. В., Параничева Т. М., Тюрина Е. В., Шибалова М. С. Влияние гаджетов на развитие детей. Новые исследования. 2019; 1: 57: 25-35.

3. Kuchma VR, Suhareva LM, Hramcov PI. Gigienicheskaja bezopasnost' zhiznedejatel'nosti detej v cifrovoj srede. Zdorov'e naselenija i sreda obitanija. 2016; 8 (281): 4-7. Russian.

4. Buhtijarov IV, Denisov Jel, Eremin AL. Osnovy informacionnoj gigieny: koncepcii i problemy innovacij. Gigiena i sanitarija. 2014; 93 (4): 5-9. Russian. 
5. Bolshakov AM, Krutko VN, Kutepov EN, Mamikonova OA, Potemkina NS, Rozenblit SI et al. Informational hygiene as a new topical branch of hygiene of children and adolescents. Gigiena sanitarija. 2016; 2: 172-7. Russian.

6. Sankov SV. Gigienicheskaja bezopasnost' jelektronnoj informacionno-obrazovatel'noj sredy $\vee$ sovremennoj shkole (nauchnyj obzor). Voprosy shkol'noj i universitetskoj mediciny i zdorov'ja. 2018; 2: 13-20. Russian.

7. Koncepcija informacionnoj bezopasnosti detej. Rasporjazhenie pravitel'stva RF \# 2471-r (02 dekabrja 2015). Avialable from: http://static.government.ru/media/files/mPbAMyJ29uSPhL3p20 168GA6hv3CtBxD.pdf. Russian.

8. Janushanec OI, Petrova NA, Bezzubenkova EF, Neljubova EA, Shirokova AJu. Gigienicheskaja ocenka tehnicheskogo osnashhenija realizacii informacionnyh tehnologij, ispol'zuemyh v obuchenii shkol'nikov. V sbornike: Profilakticheskaja medicina-2019: sbornik nauchnyh trudov Vserossijskoj nauchno-prakticheskoj konferencii s mezhdunarodnym uchastiem. 14-15 nojabrja 2019 goda. SPb.: Izd-vo SZGMU im. I. I. Mechniko-va, 2019: 244-50. Russian.

9. Kuchma VR, Suhareva LM, Hramcov PI. Sovremennye podhody k obespecheniju gigienicheskoj bezopasnosti zhiznedejatel'nosti detej $\vee$ giperinformacionnom obshhestve. Voprosy shkol'noj i universitetskoj mediciny i zdorov'ja. 2015; 3: 22-27. Russian

10. Kuchma VR, Teksheva LM, Kurganskiy AM, Petrenko AO Hygienic assessment of the use of readers in elementary school. Gigiena i sanitarija. 2014; 93 (3): 57-60. Russian.

11. Kuchma VR, Rapoport IK, Sokolova SB, Aleksandrova IYe, Makarova AYu, Mustafaeva KSh i dr. Rasprostranennost' i ocenka ispol'zovanija jelektronnyh ustrojstv $v$ uchebnoj i dosugovoj dejatel'nosti shkol'nikov 7-8 klassov. Sechenovskij vestnik. 2015; 3 (21): 43-50. Russian.

12. Laks M, Guerra SM, Miraglia JL, Medeiros EA. Distance Learning in Antimicrobial Stewardship: Innovation in Medical Education. PMID: 31174524; PMCID: PMC6555969; DOI: 10.1186/s12909019-1623-x. Russian.

13. Maria B, Oleksandr K, Valentina E, Olena Y. Distance-pedagogical technologies in olympic education for schoolchildren. Journal of Physical Education and Sport. Journal of Physical Education and Sport. 2019; 378 (4): 2497-503. Ukraine.

14. Druzhilov SA. Gigienicheskie aspekty informacionno-tehnologicheskoj zavisimosti cheloveka v novoj real'nosti. Gigiena i sanitarija. 2019; 98 (7): 748-53. Russian.

15. Smirnova AA, Sinogina ES. Vlijanie komp'jutera i seti internet na fizicheskoe i psihicheskoe zdorov'e shkol'nikov. Narodnoe obrazovanie. 2017; 1 (2): 199-204. Russian.

16. Kuchma VR, Tkachuk EA, Tarmaeva IYu. Psychophysiological state of children in conditions of informatization of their life activity and intensification of education. Gigiena i sanitarija. 2016; 12: 1183-8. Russian.

17. Lemola S, Perkinson-Gloor N, Brand S, Dewald-Kaufmann JF, Grob A. Adolescents' electronic media use at night, sleep disturbance, and depressive symptoms in the smartphone age. J Youth Adolesc. 2015; 44 (2): 405-18.

18. Shutova NV, Baranova YuM. Risk assessment of internet addiction for the mental health of adolescents. Gigiena i sanitarija. 2017; 96 (6): 568-72. Russian.

19. Kuchma VR, Stepanova MI, Sazanyuk ZI, Polenova MA, Aleksandrova IE, Berezina NO, Makarova AYu. The hygienic estimation of training sessions using electronic tablet on functional state of students. Sechenov Medical Journal. 2015; 3 (21): 3542. Russian.

20. Rideout VJ, Foehr UG, Roberts DF. Generation M2: Media in the Lives of 8- to 18-Year-Old. Henry J. Kaiser Family Foundation, Menlo Park, California. 2010. Available from: http://www.kff.org/ entmedia/upload/8010.pdf

21. Pope-Ford R. Back flexion and extension: The effects of static posture on children using mobile devices. In: Advances in Intelligent Systems and Computing. AHFE International Conference on Safety Management and Human Factors, 2018; Orlando; United States; 21-25 July 2018. 2019; 791: 342-51.

22. Butuhanov VD. K voprosu valeologicheskih problem dvigatel'noj aktivnosti i zdorov'ja shkol'nikov. Bjulleten' Vostochno-Sibirskogo nauchnogo centra Sibirskogo otdelenija Rossijskoj akademii nauk. 2009; 2: 227-8. Russian.

23. Milushkina OYu, Skoblina NA, Markelova SV, Tatarinchik AA, Bokareva NA, Fedotov DM Assessing health risk for schoolchildren and students caused by exposure to educational and entertaining information technologies. Health Risk Analysis. 2019; 3: 135-43. Russian.

24. Wimalasundera S. Computer vision syndrome. Galle Medical. 2006; 11 (1): 201-4.

25. Skoblina NA, Milushkina OYu, Tatarinchik AA, Fedotov DM, Tsameryan AP, Dobruk IV, et al. Hygienic problems of vision protection in schoolchildren and students in a hyper-information society. Russian ophthalmology of children. 2017; 4: 5-9. Russian.

26. Teksheva LM, Jelksnina EV, Perminov MA. Gigienicheskie aspekty ispol'zovanija komp'juternyh sredstv obuchenija $\vee$ sisteme obshhego obrazovanija. Gigiena i sanitarija. 2007; 4: 65-69. Russian.

27. Markelova SV. The role of printed and electronic publications in development of vision disorders. Fundamental and Clinical Medicine. 2019; 4 (4): 97-104. Russian.

28. Kuchma VR, Suhareva LM, Rapoport IK, Shubochkina El, Skoblina NA, Milushkina OYu. Population health of the children, health risks, sanitary and epidemiological well-being of students: problems, solutions, technology activities. Gigiena i sanitarija. 2017; 96 (10): 990-5. Russian.

29. Zdravoohranenie $\vee$ Rossii 2017: statisticheskij sbornik. Rosstat. M., 2017. Available from: https://www.gks.ru/storage/mediabank/ zdrav17.pdf. Russian.

30. Lukyanec GN, Makarova LV, Paranicheva TM, Tyurina EV, Shibalova MS. Vlijanie gadzhetov na razvitie detej. Novye issledovanija. 2019; 1: 57: 25-35. Russian. 